\title{
Type IV Collagen Induces Matrix Metalloproteinase 2 Activation in HT1080 Fibrosarcoma Cells
}

\author{
Erik Maquoi, ${ }^{*}$ Francis Frankenne, ${ }^{*}$ Agnès Noël, ${ }^{*}$ Hans-Willi Krell ${ }^{\dagger}$, Frank Grams, ${ }^{\star}$ and Jean-Michel Foidart* \\ *Laboratoire de Biologie des Tumeurs et du Développement, Université de Liège, Tour de Pathologie (B23), Sart Tilman, B-4000 Liège, \\ Belgium; ${ }^{\dagger}$ Boehringer Mannheim, GmbH, Penzberg, Germany; and ${ }^{\star}$ Boehringer Mannheim, GmbH, Mannheim, Germany
}

\begin{abstract}
Matrix metalloproteinase 2 (MMP-2) activation has been described as a "master switch" which triggers tumor spread and metastatic progression. We show here that type IV collagen, a major component of basement membranes, promotes MMP-2 activation by HT1080 cells. When plated on plastic, HT1080 cells constitutively processed the $66-\mathrm{kDa}$ pro-MMP-2 into a $62-\mathrm{kDa}$ intermediate activated form, most probably through a membrane type (MT) 1 MMP-dependent mechanism. In the presence of type IV collagen, part of this intermediate form was further processed to fully activated 59-kDa MMP-2. This activation was prevented by tissue inhibitor of MMP (TIMP)-2 and a broad-spectrum hydroxamic acid-based synthetic MMP inhibitor (GI129471). Type IV collagen-mediated pro-MMP-2 activation did not involve either a transcriptional modulation of MMP-2, MT1-MMP, or TIMP-2 expression nor any alteration of MT1-MMP protein synthesis or processing. An inverse relationship between MMP-2 activation and the concentration of secreted TIMP-2 was observed. This is consistent with our previous report that TIMP-2 degradation is probably linked to the MT1MMP-dependent MMP-2 activation mechanism. Because invasive tumor cells must breach basement membranes at different steps of the metastatic dissemination, the ability of HT1080 cells to activate pro-MMP-2 in the presence of type IV collagen might represent a key regulatory mechanism for the acquisition of an invasive potential.
\end{abstract}

\section{INTRODUCTION}

The active degradation of the basement membrane (BM) is required for tumor invasion and subsequent metastatic dissemination [1]. Indeed, BM are present at key points in the metastatic cascade. Escape of malignant cells from the primary tumor in epithelial neoplasias, intravasation and extravasation during hematogenous dissemination, and perineural and muscular invasion require BM breaching by proteolytic degradation [2-4]. Accordingly, interactions between tumor cells and the ECM have emerged as pivotal events of the metastatic phenotype.

Among proteinases, including serine proteinases, cysteine proteinases, and matrix metalloproteinases (MMPs), that have been implicated in tumor cell invasion process [5], MMPs appear to be primarily responsible for much of the extracellular matrix (ECM) degradation observed during this process. Due to its unusual ability to cleave and degrade triple-helical type IV collagen (the major structural component of the BM), MMP-2 (also known as gelatinase A) overexpres-sion by tumor cells and/or their associated stroma was considered as a key event during tumor progression and metastasis $[6,7]$. Nevertheless, overproduction of the proenzyme is not sufficient for the acquisition of an invasive phenotype [8]. Indeed, most MMPs are produced as latent zymogens which require a proteolytic processing of their N-terminal region to gain catalytic activity. This activity is further controlled by a family of specific endogenous tissue inhibitors of MMPs: the TIMPs [9]. In this context, the close association observed between MMP-2 activation and metastatic progression in various tumors [10-12] suggests that MMP-2 activation represents a "master switch" triggering tumor spread.

MMP-2 activation is mediated by a membrane-associated mechanism that can be induced in vitro by tumor necrosis factor- $\alpha$, concanavalin A (ConA), cytochalasin D, and phorbol esters such as tetradecanoylphorbol 13ace-tate (TPA) [13-21]. Sato and co-workers have identified MT1-MMP (membrane type 1 MMP or MMP-14): a MMP possessing a hydrophobic C-terminal transmembrane domain, which is considered as a physiological MMP-2 activator [22-25]. The active form of MT1-MMP, which is generated through a furin-dependent mechanism [26, 27], binds TIMP-2 through the interaction of the N-terminal domains of each protein, thereby docking soluble TIMP-2 to the cell surface [20, 28-30]. This bimolecular complex subsequently functions as a receptor for the secreted pro-MMP-2, through interactions of their C-terminal domains, thus forming a MT1MMP/TIMP-2/MMP-2 ternary complex. In the presence of uncomplexed active MT1-MMP, the prodomain of plasma membrane-bound MMP-2 is cleaved between $\mathrm{Asn}^{37}$ and $\mathrm{Leu}^{38}$, thus generating a 62-kDa intermediate 
activated form. When present at a sufficiently high concentration on the cell surface, this intermediate is further processed to the fully activated 59-kDa MMP-2 by an intermolecular auto lytic cleavage between $\mathrm{Asn}^{80}$ and $\mathrm{Tyr}^{81}$ [31]. Alternatively, this second cleavage can be achieved through the action of plasmin [32]. However, the mechanisms regulating this activation process in vivo remain uncertain.

Proteins of the ECM, such as collagens, fibronectin, and laminin, have dynamic functions in the regulation of a number of cellular mechanisms including cell adhesion, spreading, differentiation, and migration as well as cell death [33-35]. Therefore, cell-matrix interactions are likely to play significant roles in the regulation of cellular proteolysis [36]. Accordingly, different reports have emphasised the involvement of ECM components including fibronectin, bone matrices proteins such as osteopontin and bone sialoprotein [37, 38], and type I collagen [39$44]$ in the induction of pro-MMP-2 activation.

In the present study, we have investigated the potential influence of different ECM components on pro-MMP-2 activation by a human fibrosarcoma cell line (HT1080) and compared it with ConA- and TPA-induced activation mechanisms.

\section{MATERIAL AND METHODS}

\section{Cell culture.}

HT1080 human fibrosarcoma were maintained in Dulbecco's modified Eagle's medium (DMEM) supplemented with $10 \%(\mathrm{v} / \mathrm{v})$ heat-inactivated fetal calf serum (FCS), penicillin-streptomycin (100 IU/ml-100 $\mu \mathrm{g} / \mathrm{ml}), 2 \mathrm{mM}$ glutamine, and $10 \mathrm{mM}$ Hepes buffer at $37^{\circ} \mathrm{C}$ in a humid atmosphere $\left(5 \% \mathrm{CO}_{2}-95 \%\right.$ air). All culture reagents were purchased from Gibco-Life Technologies (Merelbeke, Belgium).

Human recombinant TIMP-2 (rTIMP-2) was obtained from CHO cells transfected with pDSRa2 vector containing human TIMP-2 cDNA. rTIMP-2 was purified as described [45]. The broad-spectrum synthetic MMP inhibitor GI129471 [46] was prepared as $10 \mathrm{mM}$ stock solution in dimethyl sulfoxide (DMSO) and used at final concentrations ranging from 1 to $1000 \mathrm{nM}$ in $0.1 \%$ DMSO.

\section{Coating of culture wells with ECM components.}

Laminin and fibronectin were purified from Engelbreth-Holm-Swarm tumors [47] and from human plasma by gelatin affinity chromatography [48]. Type I collagen was prepared from fetal calf skin [49] and type IV collagen was purified from human placenta (kindly provided by H. W. Krell, Boehringer Mannheim, Penzberg, Germany).

Ninety-six well plates (Falcon, Becton-Dickinson, Meylan, France) were coated (100 $\mu 1 /$ well) with the different ECM components [diluted at $10-600 \mu \mathrm{g} / \mathrm{ml}$ in phosphate-buffered saline (PBS)] or PBS alone (control). Coats were left to air dry overnight in a laminar flow hood under UV light. Before use, coated wells were washed twice with water and incubated for $1 \mathrm{~h}$ in serum-free DMEM at $37^{\circ} \mathrm{C}$.

\section{Preparation of conditioned media and total cell extracts.}

Cells growing exponentially in T-75 flasks (Nunc, Roskilde, Denmark) were harvested by trypsin-EDTA treatment, washed with $10 \%$ FCS-containing medium, and allowed to recover from trypsinisation for at least 30 $\min$ at $37^{\circ} \mathrm{C}$. Cells were then washed twice in serum-free DMEM and diluted in the same medium supplemented with $0.1 \%$ bovine serum albumin (BSA, fraction V, Sigma, Bornem, Belgium) to a density of $3 \times 10^{5}$ cells $/ \mathrm{ml}$. This cell suspension $(200 \mu \mathrm{l} / \mathrm{well})$ was plated into ECM-coated or PBS-treated wells (see above). Cells plated in PBS-treated wells were subsequently supplemented with serum-free DMEM (untreated control), ConA (final concentration, $30 \mu \mathrm{g} / \mathrm{ml}$; Boehringer Mannheim, Mannheim, Germany), or TPA (final concentration, $10 \mathrm{ng} / \mathrm{ml}$; Sigma). The conditioned media were collected after different incubation times and stored frozen at $-20^{\circ} \mathrm{C}$. The resulting cell monolayers were washed once with $100 \mu 1$ serum-free DMEM and extracted with $50 \mu 1$ of Ripa buffer [50 mM Tris-HC1, pH 7.4; $150 \mathrm{mM} \mathrm{NaCl} ; 1 \%$ Nonidet P40; $1 \%$ Triton X-100; 1\% sodium deoxycholate; $0.1 \%$ sodium dodecyl sulfate (SDS); $5 \mathrm{mM}$ iodoacetamide; $2 \mathrm{mM}$ phenylmethylsulfonyl fluoride (PMSF)] for 2 $\mathrm{h}$ at $4^{\circ} \mathrm{C}$. Alternatively (for ELISA), extraction was performed by son-ication $(10 \mathrm{~s}, 100 \mathrm{~Hz})$ in $100 \mu \mathrm{l}$ of PBS supplemented with $2 \mathrm{mM}$ PMSF. 


\section{Gelatin zymography.}

Analysis of gelatinolytic activities in conditioned media and total cell extracts was performed by gelatin zymography as previously described [27],

The relative proportions of the gelatinolytic bands corresponding to the different forms of gelatinase A were evaluated by scanning densitometry using a GS-700 imaging densitometer (Bio-Rad, Hercules, CA) equipped with Molecular Analyst software. Results were expressed as relative percentages of total gelatinase A activity.

\section{Western blot analysis for MT1-MMP.}

Samples of total cell extracts were analyzed using two distinct monoclonal antibodies (mAbs): mAb IE12 directed against the N-terminal prodomain of MT1-MMP and mAb 2D7 against the hemopexin-like domain of MT1-MMP (kindly provided by P. Basset, IGBMC, Illkirch, France) as previously described [27],

\section{Isolation of RNA and Northern blot analysis.}

Total RNA was extracted from the cell monolayers by RNAzol B treatment (Biogenesis, Bournemouth, UK). An aliquot of RNA $(15 \mu \mathrm{g})$ was electropho-resed through agarose gels containing 10\% formamide and transferred onto a nylon membrane (Hybond-N, Amersham, Gent, Belgium). The membrane was hybridized with MMP-2, MT1-MMP, TIMP-1, and TIMP-2 cDNA probes labeled with ${ }^{32} \mathrm{P}$ using random priming synthesis (Boehringer Mannheim). The membrane was re-hybridised to a human 28S-rRNA oligonucleotide probe (Clontech, Palo Alto, CA), which served as an internal control. The amounts of the different transcripts were quantified by densitometric analysis of autoradiographs of the Northern blots. All results were corrected for RNA loading as a function of the densitometric data obtained for the 28S-rRNA signals.

\section{TIMP-2 quantification by ELISA.}

TIMP-2 concentrations in conditioned media and total cell extracts were determined using a sandwich ELISA as described [50]. Briefly, rTIMP-2 (see above) was used to raise polyclonal antibodies in rabbit (RA Abs) and in embryonated chicken eggs (SMI Abs). The specific anti-rTIMP-2 IgGs from chicken were purified by ammonium sulfate precipitation [51]. RA pAbs were purified by affinity chromatography. RA Abs were adsorbed onto Maxisorp 96-well plates (Nunc) by overnight incubation at $4^{\circ} \mathrm{C}$. Wells were subsequently saturated overnight at $4^{\circ} \mathrm{C}$ with $100 \mu \mathrm{l}$ of PBS buffer supplemented with $3 \%$ BSA and $0.05 \%$ Tween 20 . Test samples $(50 \mu \mathrm{l})$ were added to each well and incubated overnight at $4^{\circ} \mathrm{C}$. After three washes with $200 \mu \mathrm{l}$ of PBS$0.05 \%$ Tween 20 and an incubation with the SMI Abs for $1 \mathrm{~h}$ at $37^{\circ} \mathrm{C}$, bound TIMP-2 was revealed using peroxidase-conjugated rabbit anti-chicken IgGs (Organon Teknica, Turnhout, Belgium) for $1 \mathrm{~h}$ at $37^{\circ} \mathrm{C}$. After extensive washing with water, ABTS (750 mg/liter; Boehringer Mannheim) and $0.004 \% \mathrm{H}_{2} \mathrm{O}_{2}$ in ABTS buffer ( $\mathrm{pH}$ 5.6) were added for $1 \mathrm{~h}$ at $37^{\circ} \mathrm{C}$. Absorbances were measured at $405 \mathrm{~nm}$ using an automated microtiter plate reader (Multiscan MS, Labsystems, Zellik, Belgium). The sensitivity of this ELISA for TIMP-2 was $0.3 \mathrm{ng} / \mathrm{ml}$, and the dose-response curve is linear within the $0.6-20 \mathrm{ng} / \mathrm{ml}$ range. Each sample was analysed in duplicate.

\section{Invasion assay.}

HT1080 cell chemoinvasion through type IV collagen ( $22 \mu \mathrm{g} /$ insert $)$ and chemotaxis were assayed using Transwell cell culture inserts (Costar) as previously described [27],

\section{Cell surface binding and degradation of ${ }^{125}$ I-TIMP-2.}

rTIMP-2 was iodinated to a specific activity of 20-40 $\mu \mathrm{Ci} / \mu \mathrm{g}$ using the Iodo-Gen technique (Pierce, Rockford, IL). Briefly, $0.8 \mathrm{mCi}$ of ${ }^{125} \mathrm{I}^{-}\left(\mathrm{Na}{ }^{125} \mathrm{I}\right.$, Amersham, Gent, Belgium) was added to $10 \mu \mathrm{g}$ of rTIMP-2 in $35 \mu 1$ of 0.5 $\mathrm{M}$ sodium phosphate ( $\mathrm{pH}$ 7.5). This solution was transferred into a 1.5-ml Eppendorf tube coated with $10 \mu \mathrm{g}$ of Iodo-Gen. After a 2-min incubation, the reaction was blocked by transferring the reaction mixture into $0.2 \mathrm{ml}$ of $0.05 \mathrm{M}$ sodium phosphate ( $\mathrm{pH} 7.5$ ). Monomeric ${ }^{125} \mathrm{I}-\mathrm{rTIMP}-2$ was separated from free ${ }^{125} \mathrm{I}^{-}$and potentially aggregated forms by filtration through a 0.9 x 50-cm column (Econo column, Bio-Rad) of S200 Sephacryl resin (Pharmacia, Uppsala, Sweden). Assays of ${ }^{125}$ I-rTIMP-2 binding and degradation by cells plated in 96-well plates (see above) were performed in triplicate as follows. After adhesion, confluent cell monolayers were supplemented with ${ }^{125}$ I-rTIMP-2 up to a final concentration of $0.6 \mathrm{nM}$ for indicated culture periods. Nonspecific binding was evaluated by incubating ${ }^{125}$ I-rTIMP-2 without cells. Culture supernatants were collected after different incubation periods, immediately mixed with an equal volume of reducing sample buffer (with $700 \mathrm{nM}$ 
$\beta$-mercapto-ethanol), and stored at $+4^{\circ} \mathrm{C}$ until electrophoresis. Cell monolayers were washed once with $100 \mu \mathrm{l}$ of serum-free DMEM containing $0.1 \%$ BSA and extracted with $50 \mu 1$ of Ripa buffer supplemented with PMSF; the radioactivity associated with the total cell extracts was measured in a $\gamma$-counter. Specific binding was calculated by subtracting the nonspecific radioactivity (wells without cells) from cell-extract-associated radioactivity. Results are expressed as percentages of the total radioactivity added per well.

Polyacrylamide gel electrophoresis (PAGE).

Samples collected from ${ }^{125}$ I-rTIMP-2 binding assays were boiled for $5 \mathrm{~min}$ and subjected to electrophoresis on SDS-15\% PAGE. Once dry, gels were autora-diographied and the percentages of degraded ${ }^{125}$ I-rTIMP-2 were calculated based on densitometric analysis of autoradiographs.

\section{RESULTS}

\section{ECM Components Modulate Pro-MMP-2 Activation}

To investigate the effect of ECM components on pro-MMP-2 synthesis and activation by HT1080 cells, conditioned media and total cell extracts obtained from cells cultured on plastic, type I or type IV collagen, laminin, or fibronectin were analyzed by gelatin zy-mography. TPA and ConA, two nonphysiological inducers of MMP-2 activation, were used as positive controls.

When HT1080 cells were cultured on plastic for $24 \mathrm{~h}$, conditioned medium essentially contained two gelatinolytic bands of 66 and $92 \mathrm{kDa}$, corresponding respectively to the MMP-2 and MMP-9 proforms (Fig. 1A, lane 1). The corresponding cell extract yielded a major 66-kDa pro-MMP-2 and a faint $62-\mathrm{kDa}$ gelatinolytic band (Fig. IB, lane 1). This latter band represents an intermediate activated form of MMP-2 which has been previously shown to result from a MT1-MMP-depen-dent proteolytic processing of pro-MMP-2 [20, 31, 32]. After $48 \mathrm{~h}$, the amount of $62-\mathrm{kDa}$ MMP-2 increased in both conditioned medium and cell extract [accounting for 10 and $35 \%$ of total MMP-2 activity, respectively (Figs. 1A and 1B, lane 7)]. Despite its high concentration in the cell extract, this $62-\mathrm{kDa}$ MMP-2 was not further processed to generate the fully mature 59-kDa MMP-2 species.

In TPA-treated $(10 \mathrm{ng} / \mathrm{ml})$ cells, the 62-kDa MMP-2 was already detectable in both conditioned medium and total cell extract after $24 \mathrm{~h}$ (Figs. 1A and 1B, lane 2). After $48 \mathrm{~h}$, the secreted 62-kDa MMP-2 was slightly converted into the 59-kDa mature species (Fig. 1A, lane 8). TPA treatment also increased the cell-associated MMP-9 level (Fig. 1B, lanes 2 and 8).

Activation of pro-MMP-2 was also strongly promoted by ConA $(30 \mu \mathrm{g} / \mathrm{ml})$. In contrast to TPA, ConA-treated cells further processed the $62-\mathrm{kDa}$ intermediate MMP-2 to the fully mature 59-kDa form (Figs. $1 \mathrm{~A}$ and $1 \mathrm{~B}$, lanes 3 and 9). This ConA-mediated activation generated high levels of mature MMP-2 (about 12 and 30\% of total MMP-2 activity after $24 \mathrm{~h}$ in conditioned medium and total cell extract, respectively). After a longer incubation (48 h), the mature 59-kDa form was the major MMP-2 species present in both conditioned medium and total cell extract (accounting for 45 and 50\% of total MMP-2 activity, respectively) (Figs. 1A and 1B, lane 9).

When HT1080 cells were plated on thin coats of type IV or type I collagen (20 $\mu \mathrm{g} / \mathrm{well})$, a faint $62-\mathrm{kDa}$ intermediate MMP-2 form was detected in the 24-h cell extracts but not in the corresponding conditioned media (Figs. 1A and 1B, lanes 4 and 5). During the next $24 \mathrm{~h}$, this $62-\mathrm{kDa}$ band was partially converted into the 59-kDa form (Figs. 1A and 1B, lanes 10 and 11). Despite their similar abundance in cell extracts obtained from cells cultured on type IV or type I collagens (Fig. IB, lanes 10 and 11), the two activated MMP-2 forms were about three times more abundant in type IV than in type I collagen-derived conditioned media (Fig. 1A, lanes 10 and 11), suggesting that the type IV collagen-induced MMP-2 activation was more efficient.

In contrast to type IV and type I collagens, neither fibronectin $(20 \mu \mathrm{g} / \mathrm{ml}$, Figs. 1A and 1B, lanes 6 and 12) nor laminin $(20 \mu \mathrm{g} / \mathrm{ml}$, data not shown) was able to modulate pro-MMP-2 activation by HT1080 cells. 
Figure 1: Influence of TPA, ConA, and ECM components on pro-MMP-2 activation by HT1080 cells. Cells were cultured for 24 (lanes 1-6) or 48 h (lanes 7-12) on plastic without additional treatment (lanes 1 and 7), plastic with TPA (10 $\mathrm{ng} / \mathrm{ml}$, lanes 2 and 8), or ConA (30 $\mu \mathrm{g} / \mathrm{ml}$, lanes 3 and 9) treatment, type IV collagen (20 $\mu \mathrm{g} / \mathrm{well}$, lanes 4 and 10), type I collagen (20 $\mathrm{g} /$ well, lanes 4 and 11), or fibronectin (20 $\mu \mathrm{g} /$ well, lanes 6 and 12).

Conditioned media $(A)$ and total cell extracts $(B)$ were subjected to gelatin zymography. Scanning densitometry of the gels depicted in $A$ and $B$ was used to quantify pro-MMP-2 activation. The relative proportions of MMP-2 activated intermediate $(62-k D a ; \square)$ and mature $(59-k D a ;-)$ species are expressed as percentages of total MMP2 .

\section{A}

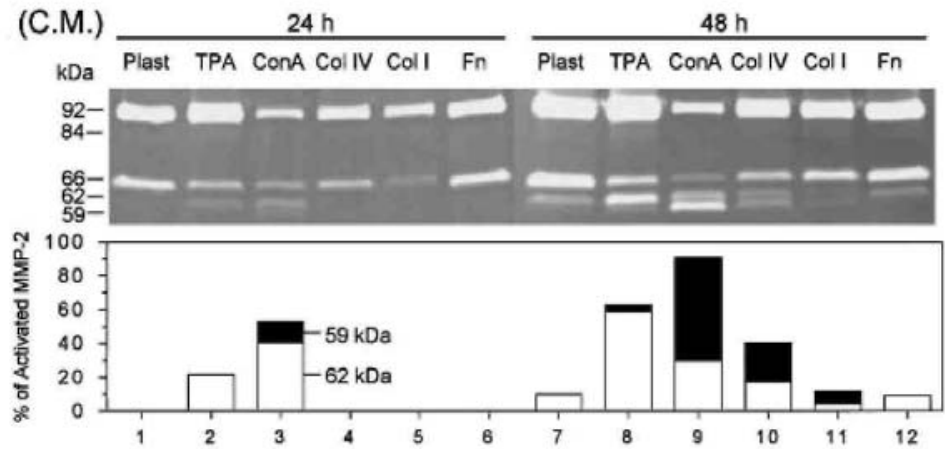

B

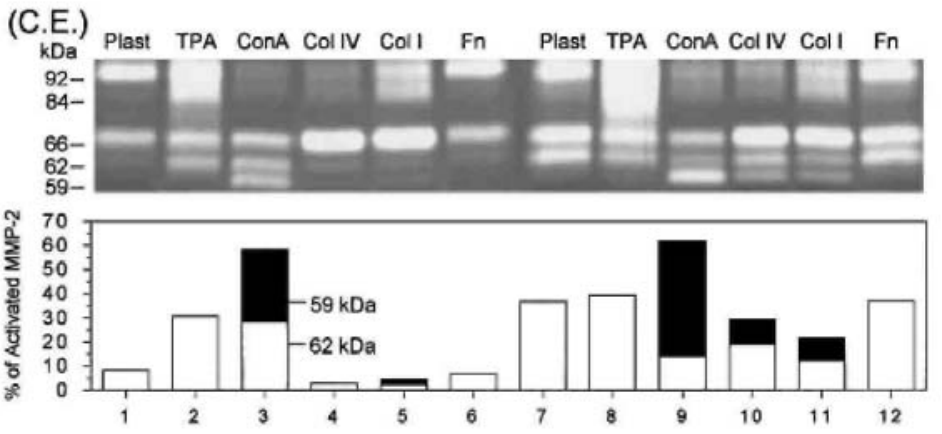

Figure 2: Influence of collagens concentration on pro-MMP-2 activation by HT1080 cells. HT1080 were cultured in 96 well plates coated with increasing concentrations of type IV or type I collagens (0-60 $\mu g$ of protein/well). After $48 \mathrm{~h}$, culture medium was removed and the resulting cell monolayers were washed in serumfree DMEM, extracted in Ripa buffer, and subjected to gelatin zymogra-phy. Pro-MMP-2 activation was quantified after scanning densitometry of the gels. The relative proportions of activated MMP-2 forms (62 kDa + $59 \mathrm{kDa}$ ) are expressed as percents of total MMP-2.

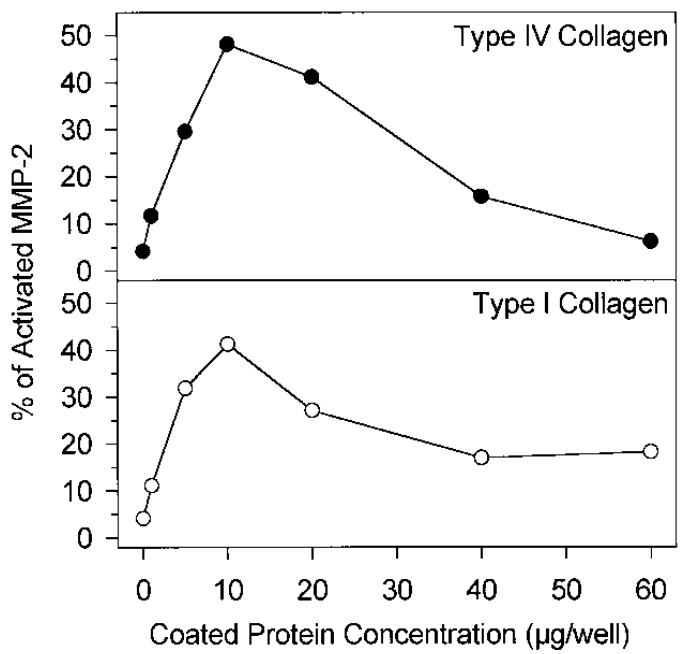




\section{Type IV and Type I Collagens Promote MMP-2 Activation in a Dose-Dependent Manner}

It is now well established that the activation of pro-MMP-2 is a membrane-associated mechanism. In order to further characterize the influence of the ECM components on pro-MMP-2 activation, we prepared cellular extracts from HT1080 cells plated on increasing concentrations of type I or type IV collagens (0-60 $\mu \mathrm{g} / \mathrm{well})$. A maximal stimulation of pro-MMP-2 activation was observed for collagen concentrations ranging from 10 to 20 $\mu \mathrm{g}$ per well. At higher concentrations, the stimulatory effect of both collagens was reduced (Fig. 2). The analysis of the corresponding conditioned media gave similar results (data not shown).

The promoting effect of type IV or type I collagens on pro-MMP-2 activation was cell dependent since no activation was observed when supernatants of HT1080 cells plated for $48 \mathrm{~h}$ on plastic were further incubated for 24 or $48 \mathrm{~h}$ on collagen coats (data not shown). However, it should be noted that type IV and, to a lesser extent, type I collagen have the ability to bind pro-MMP-2 (Fig. 3) and its two activated forms (data not shown).

\section{MMP Inhibitors Block Pro-MMP-2 Activation and Reduce Cell Invasiveness through Type IV Collagen}

To investigate the proteolytic process leading to pro-MMP-2 activation, HT1080 cells plated on type IV collagen were treated with increasing concentrations of rTIMP-2 or GI129471 (a broad-spectrum synthetic MMP inhibitor). rTIMP-2 dose dependently prevented the conversion of the 66-kDa pro-MMP-2 into the 62-and 59$\mathrm{kDa}$ activated forms, with inhibition of this processing being complete at $100 \mathrm{nM}$ (Fig. 4A). A similar dosedependent blockage of pro-MMP-2 processing was observed with GI129471 (Fig. 4C), thus confirming that proMMP-2 is activated through an MMP-dependent pathway.

To determine whether this inhibition of pro-MMP-2 activation by rTIMP-2 or GI129471 influences the ability of HT1080 cells to invade through type IV collagen, chemoinvasion assays were performed (Figs. 4B and 4D, respectively). Supplementation of the culture medium with rTIMP-2 or GI129471 dose dependently inhibited the number of cells that breached the layer of type IV collagen and migrated to the lower side of the insert. A maximal 80\% inhibition of HT1080 invasion was obtained with $100 \mathrm{nM}$ rTIMP-2 (Fig. 4B) or $1 \mu$ M GI129471 (Fig. 4D). It should be noted that these treatments did not significantly alter either the cellular viability (data not shown) nor the ability of the cells to freely migrate through uncoated inserts (as measured by the chemotaxis assay, Figs. 4B and 4D). These observations strongly suggest that the lower invasion extend, as measured in the presence of these two MMP inhibitors, most probably results from the blockage of pro-MMP-2 activation.

Figure 3: Pro-MMP-2 binding to type I and type IV collagens. Conditioned medium obtained from HT1080 cultured for 24 h on plastic was incubated in 96-well plates coated with increasing concentrations (0-20 $\mu \mathrm{g} /$ well) of type I or type IV collagens. After $48 \mathrm{~h}$, culture media were removed and ECM coats were washed in serum-free DMEM, extracted in Ripa buffer, and subjected to gelatin zy-mography. The amount of ECM-bound pro-MMP-2 was quantified after scanning densitometry of the gels and expressed in arbitrary units.

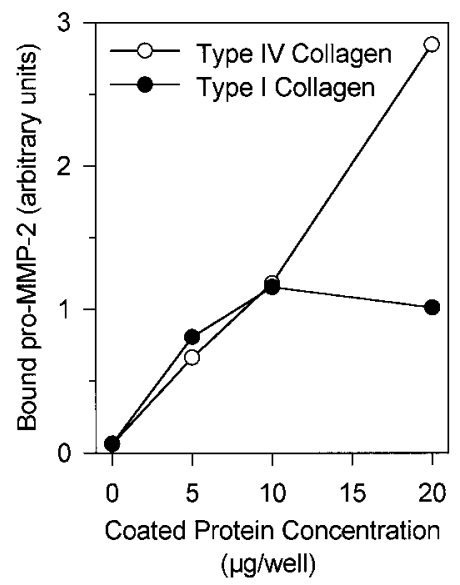


Figure 4: MMP inhibitors block pro-MMP-2 activation and reduce HT1080 invasiveness through type IV collagen. HT1080 cells were plated on type IV collagen $(20 \mu \mathrm{g} /$ well) coats and incubated with increasing concentrations of rTIMP-2 ( $A$ and B) or GI129471 (C and D). Conditioned media were collected after $48 \mathrm{~h}$ and subjected to gelatin zymography (A and C). (A) HT1080 cells were cultured in the absence (lane 1; medium) or presence of $0.1 \mathrm{nM}$ (lane 2), $1.0 \mathrm{nM}$ (lane 3), $10 \mathrm{nM}$ (lane 4), $100 \mathrm{nM}$ (lane 5), and $1000 \mathrm{nM}$ (lane 6) rTIMP-2. (C) HT1080 cells were treated with 10 nM (lane 2), 100 nM (lane 3), and 1000 nM (lane 4) GI129471 or vehicle alone (lane 1; DMSO). The influence of rTIMP-2 (B) and GI129471 (D) on HT1080 chemoinva-sion and chemotaxis was measured by using Transwell cell culture inserts coated or not with type IV collagen (22 $\mu \mathrm{g}$ (insert), respectively. HT1080 cells were incubated with increasing concentrations of inhibitors and the number of migrated cells was determined by visually counting the number of cells present on the lower side of the inserts. Results are expressed as the mean $\pm S D$ percentage of the migration of control cells. $* P<0.05$ compared to controls using the Student's t test.

A

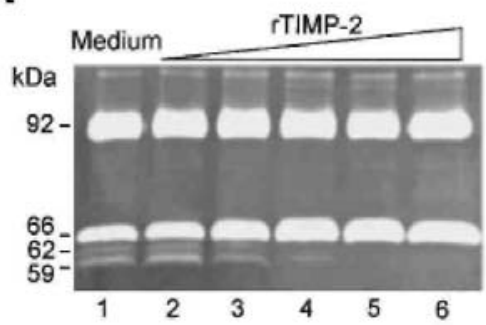

B

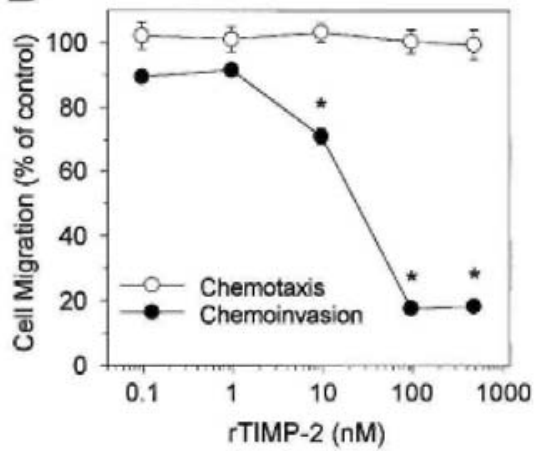

C

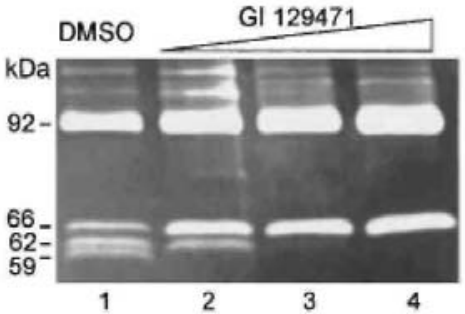

D

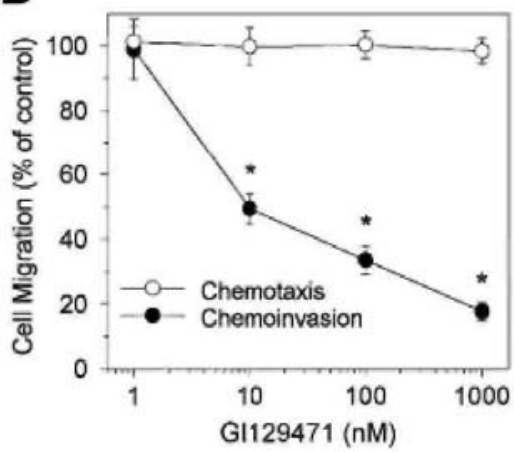

Type IV Collagen Does Not Modify the MMP-2, MT1-MMP, or TIMP-2 mRNA Levels

To characterize the mechanism of pro-MMP-2 processing induced by the physiological and nonphysi-ological activators, we investigated the influence of these inducers on MMP-2, MT1-MMP, and TIMP-2 mRNA levels. Total RNA obtained from HT1080 cells cultured for 4, 24, and $48 \mathrm{~h}$ on plastic, on type I or type IV collagen coats, or treated with ConA $(30 \mu \mathrm{g} / \mathrm{ml})$ or TPA $(10 \mathrm{ng} / \mathrm{ml})$ were analyzed by Northern blotting. These different treatments induced only minor alterations of MMP-2, MT1-MMP, and TIMP-2 mRNA levels (Fig. 5). Among these alterations, TPA transiently increased MMP-2 mRNA level after $24 \mathrm{~h}$ (1.6-fold increase, Fig. 5A) and ConA and TPA both increased the MT1-MMP mRNA level after $48 \mathrm{~h}$ (1.9- and 1.6-fold, respectively, Fig. 5B). Moreover, ConA (2.7-fold increase) and, to a lesser extent, TPA (1.8-fold increase) treatments induced a transient accumulation of TIMP-2 mRNA after $24 \mathrm{~h}$ (Fig. 5C, lanes 4 and 5). Altogether, these results showed that neither type I nor type IV collagens induced a marked modulation of MMP-2, MT1-MMP, or TIMP-2 mRNA expression.

\section{Type IV Collagen Does Not Stimulate MT1-MMP Protein Synthesis or Activation}

Several reports have documented the involvement of MT1-MMP in pro-MMP-2 activation [22-24, 27, 31]. Therefore, we investigated the influence of the different MMP-2 activating treatments on both pro-MT1-MMP synthesis and activation (Fig. 6). When HT1080 cells were plated on plastic, three major immunoreac-tive proteins were detected by Western blotting of total cell extracts: a doublet composed of 63- and 66-kDa species, both recognized by mAb 1E12 (Fig. 6A, lane 2) and corresponding to MT1-MMP proforms [27] as well as a 60$\mathrm{kDa}$ band, revealed by mAb 2D7, corresponding to activated MT1-MMP (Fig. 6B, lane 2). Upon treatment with TPA, the 63-kDa pro-MT1-MMP level was slightly increased (Fig. 6A, lane 3). Moreover, an additional 43-kDa 
band, which was recognized by mAb 2D7, was detected (Fig. 6B, lane 3). This latter MT1-MMP species was recently identified as a cell-surface-associated inactive form which results from an MMP-dependent processing of the $60-\mathrm{kDa}$ form and whose occurrence was related to pro-MMP-2 activation [13, 52]. In contrast to TPA, ConA did not increase the level of the 63-kDa pro-MT1-MMP but it dramatically increased both 60- and 43-kDa species (Figs. 6A and 6B, lane 4). When total cell extracts obtained from HT1080 cells plated on ECM components (type I or type IV collagens or fibronectin) were analyzed, no significant qualitative nor quantitative modification of MT1-MMP synthesis or processing was observed (Figs. 6A and 6B, lanes 5-7). It should be noted that the extracts obtained from HT1080 cells plated on plastic and the ECM components also contain the 43-kDa MT1-MMP but at a very low levels [27].

Figure 5: Influence of TPA, ConA, and ECM components on MMP-2 (A), MT1-MMP (B), and TIMP-2 (C) steady-state mRNA levels. HT1080 cells were plated on plastic or type I (Col I) and type IV (Col IV) collagen

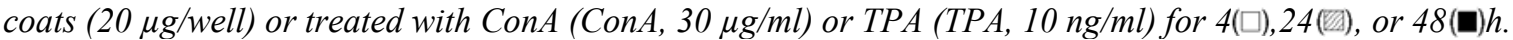
Total RNA $(10 \mu \mathrm{g})$ was electrophoresed, blotted, and hybridized as described under Materials and Methods. Levels of the different transcripts were quantified by densitometric analysis of the autoradiographs of the Northern blots. All results were corrected for RNA loading using densitometric data obtained for the $28 S-r R N A$. Results are expressed as the ratio of the optical density (OD) of each tran-script/OD of 28S-rRNA.

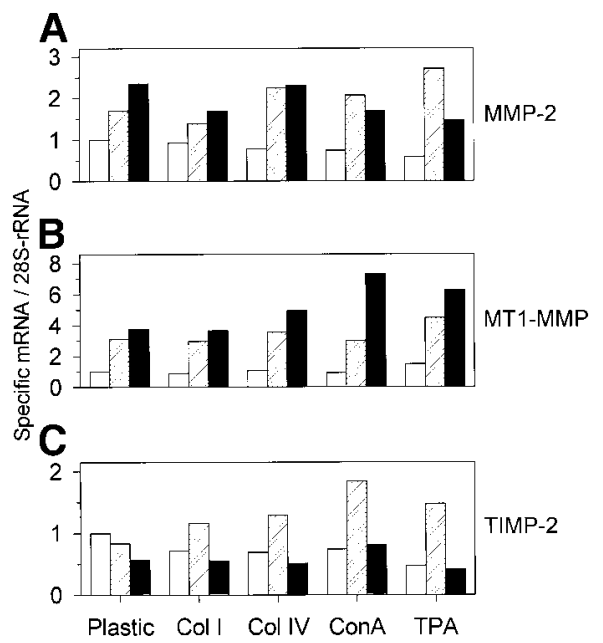

Figure 6: Influence of TPA, ConA, and ECM components on MT1-MMP synthesis and processing. HT1080 cells were cultured for $48 \mathrm{~h}$ on plastic (lane 2), type IV collagen (20 $\mu \mathrm{g} /$ well, lane 5), type I collagen (20 $\mu \mathrm{g} /$ well, lane 6), or fibronectin $(20 \mu \mathrm{g} /$ well, lane 7) or treated with TPA (10 $\mathrm{ng} / \mathrm{ml}$, lane 3) or ConA (30 $\mathrm{g} / \mathrm{ml}$, lane 4). Total cell extracts were subjected to Western blotting using $m A$ b IE 12 directed against the MT1-MMP prodomain (A) and $\mathrm{mAb} 2 \mathrm{D} 7$ directed against the MT1-MMP hemopexin-like domain (B). Extracts from COS-1 cells transiently transfected to overexpress MT1-MMP (COS-MT1) were used as a positive control (lane 1).

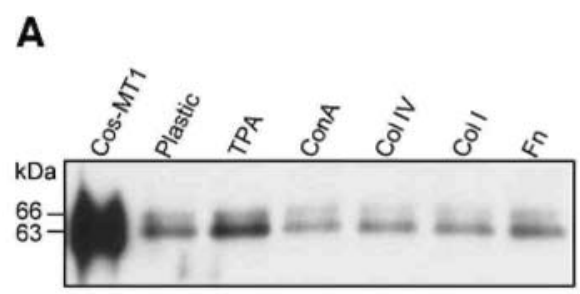

B

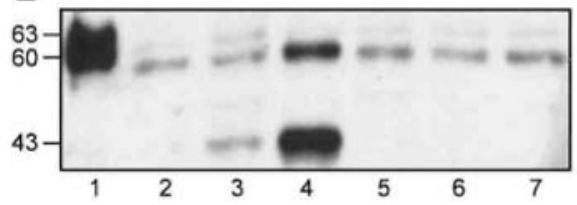




\section{Type IV Collagen Reduces TIMP-2 Concentration in HT1080 Conditioned Medium}

TIMP-2 has previously been demonstrated to play a dual role in pro-MMP-2 activation: at low concentrations, it promotes activation while, at higher concentrations, it completely inhibits this process [20, 28, 53]. To detect a potential modification of TIMP-2 concentration induced by pro-MMP-2 activating treatments, TIMP-2 concentrations in conditioned media and total cell extracts were quantified by ELISA (Fig. 7). When HT1080 cells were plated on plastic, the evolution of TIMP-2 concentration in conditioned medium was bi-phasic: it increased during the first $24 \mathrm{~h}$, reaching about $3.5 \mathrm{ng} /$ well, and then slightly decreased during the next $24 \mathrm{~h}$. In contrast, TIMP-2 concentration in total cell extract was low throughout the culture period (Fig. 7A). Culturing the cells on type I collagen $(20 \mu \mathrm{g} / \mathrm{well}$, Fig. 7B) or fibronectin $(20 \mu \mathrm{g} / \mathrm{well}$, Fig. 7C) did not significantly modify the TIMP-2 secretion profile observed on plastic (Fig. 6A). In contrast, TPA (10 ng/ml, Fig. 7D), ConA $(30 \mu \mathrm{g} / \mathrm{ml}$, Fig. 7E), and type IV collagen $(20 \mu \mathrm{g} / \mathrm{well}, \mathrm{Fig} .7 \mathrm{~F})$ treatments dramatically altered this profile.

Upon treatment with TPA, TIMP-2 concentration in conditioned medium increased steadily but remained low throughout the 48-h period (Fig. 7D). In contrast, ConA treatment induced a marked modification of TIMP-2 partitioning between conditioned medium and cell extract (Fig. 7E). Indeed, while the sum of conditionedmedium- and cell-extract-associated TIMP-2 was similar to that measured on plastic, TIMP-2 concentration in conditioned medium decreased in favor of cell extract. In the presence of type IV collagen (Fig. 7F), TIMP-2 secretion in conditioned medium displayed a similar evolution to that observed on plastic; however, TIMP-2 concentrations were about $2 \mathrm{x}$ lower than on plastic ( 2.5 and $1 \mathrm{ng} /$ well, respectively, after $48 \mathrm{~h})$. In contrast, type IV collagen-derived cell extract contained only slightly more TIMP-2 than plastic-derived one (Fig. 7F).

When HT1080 cells were plated on increasing concentrations of type IV collagen (0-60 $\mu \mathrm{g} / \mathrm{well})$, TIMP-2 secretion dose dependently decreased up to $20 \mu \mathrm{g}$ of type IV collagen/well and then slightly increased (Fig. 8). In contrast, neither type I collagen nor fibronectin was able to induce any modulation of TIMP-2 secretion (data not shown).

Figure 7: Modulation of TIMP-2 concentration in conditioned media and total cell extracts of HT1080 cells plated on ECM components or treated with either TPA or ConA. HT1080 cells were cultured for 6, 24, and 48 h on plastic (A), type I collagen $(20 \mu \mathrm{g} /$ well, B), type IV collagen $(20 \mu \mathrm{g} /$ well, $F)$, fibronectin $(20 \mu \mathrm{g} /$ well, $C)$, or treated with TPA $(10 \mathrm{ng} / \mathrm{ml}, \mathrm{D})$ or ConA $(30 \mu \mathrm{g} / \mathrm{ml}, \mathrm{E})$. TIMP-2 concentrations in conditioned media and total cell extracts were quantified by ELISA. Results are expressed as the mean $\pm S D$ amount of TIMP-2 measured in conditioned media $\left(C M, \bigcirc^{\circ}\right)$, cell extracts $(C E, \bullet)$, and total TIMP-2 (sum of TIMP-2 concentrations detected in both conditioned media and cell extracts, $C M+C E, \mathbf{\Delta})$.

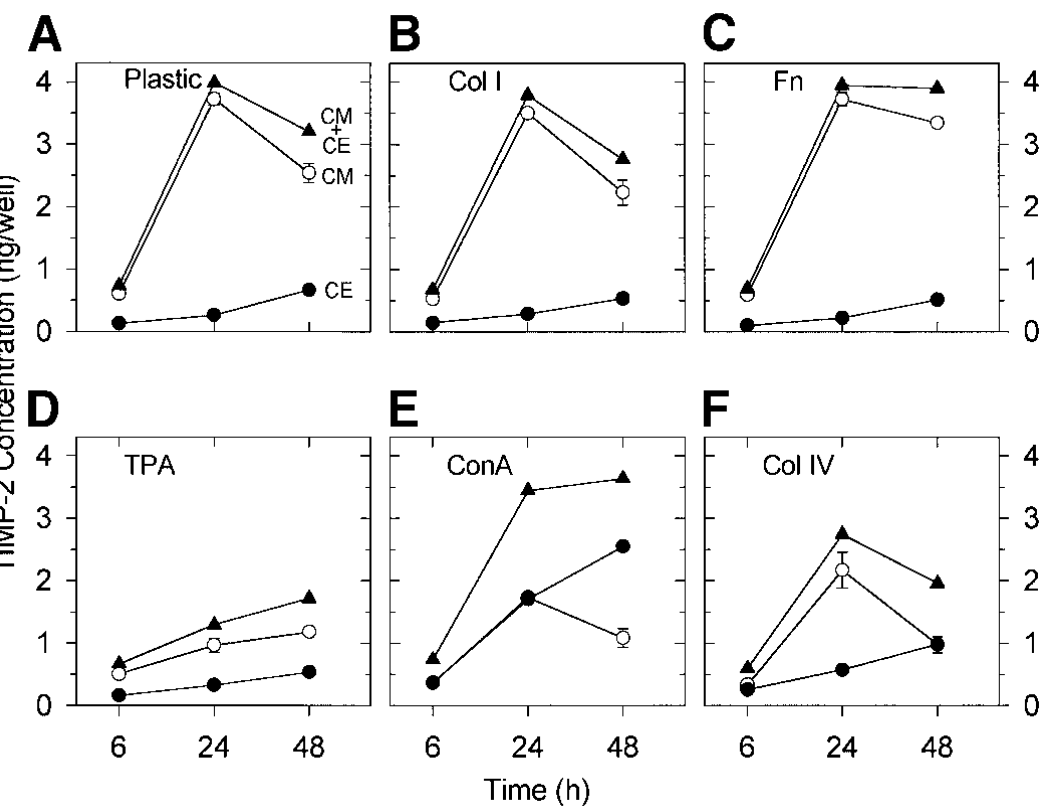


Figure 8: Dose-dependent modulation of TIMP-2 concentrations by type IV collagen. TIMP-2 concentration in conditioned medium of HT1080 cells cultured for $48 \mathrm{~h}$ on increasing concentrations (0-60 $\mu \mathrm{g} / \mathrm{well})$ of type IV collagen was quantified by ELISA. Results are expressed as the mean \pm SD TIMP-2 concentrations.

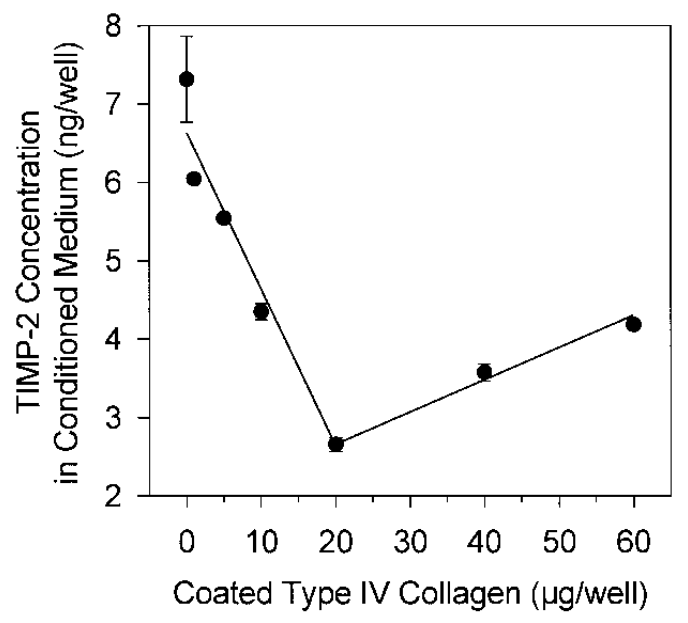

Type IV Collagen Increases TIMP-2 Degradation

In a previous study, we demonstrated that TPA treatment of HT1080 cells stimulated the internalization and degradation of TIMP-2 through a MT1-MMP-dependent mechanism, resulting in a lower level of secreted TIMP-2 [54]. To investigate the potential occurrence of a similar degradation in the presence of type IV collagen, we compared the fate of ${ }^{125}$ I-rTIMP-2 $(0.6 \mathrm{nM})$ added to HT1080 cells cultured for up to $48 \mathrm{~h}$ on plastic or type IV collagen $(20 \mu \mathrm{g} / \mathrm{well})$. Culture supernatants and cell monolayers were collected at different times and subjected to SDS-PAGE and $\gamma$-counting, respectively (Figs. 9A-9C). When ${ }^{125}$ I-rTIMP-2 was incubated alone, SDS-PAGE analysis revealed the presence of a single band of an apparent molecular mass of about $21 \mathrm{kDa}$ corresponding to the intact inhibitor (Fig. 9A). When ${ }^{125}$ I-rTIMP-2 was incubated with HT1080 cells plated on plastic or type IV collagen, the intensity of the $21-\mathrm{kDa}$ band decreased concomitantly with the appearance of an additional band, migrating just above the dye migration front (Fig. 9A). We have previously demonstrated that this low-molecular-weight band represents ${ }^{125} \mathrm{I}$-bearing peptide (s) resulting from the degradation of ${ }^{125}$ I-TIMP-2 [54]. Quantification of degraded ${ }^{125}$ I-rTIMP-2 by scanning densitometry of the autoradiographs revealed that HT1080 cells plated on type IV collagen degraded 2x more ${ }^{125}$ I-rTIMP-2 than those plated on plastic (Fig. 9B). After $48 \mathrm{~h}$ on type IV collagen, up to $65 \%$ of ${ }^{125}$ I-rTIMP-2 was degraded.

Quantification of cell-bound ${ }^{125}$ I-rTIMP-2 by $\gamma$-counting indicated that about $1 \%$ of the exogenously added ${ }^{125}$ IrTIMP-2 bound to HT1080 cells plated on plastic (Fig. 9C). In the presence of type IV collagen, the percentage of cell bound ${ }^{125}$ I-rTIMP-2 reached 5\%, thereby demonstrating that the lower level of secreted TIMP-2 measured by ELISA (Fig. 7F) results from its binding to the cell surface and more importantly from its degradation.

\section{Type IV Collagen-Mediated TIMP-2 Degradation Is Inhibited by a Synthetic MMP Inhibitor}

Because TIMP-2 was shown to bind to the cell surface by interacting with the active site of MT1-MMP [28, 30], we examined the influence of GI129471 on type IV collagen-stimulated TIMP-2 binding and degradation by HT1080 cells. Such synthetic inhibitors have previously been shown to bind to the active site of MMPs [55], thus competing with TIMP-2 for binding to MT1-MMP [28, 33, 54]. HT1080 cells plated on type IV collagen were incubated for up to $48 \mathrm{~h}$ with or without $1 \mu \mathrm{M}$ GI129471 and TIMP-2 concentrations in conditioned media and total cell extracts were determined by ELISA (Fig. 9D). In the presence of GI129471, cell-associated TIMP2 level was reduced (Fig. 9D, inset) concomitant with a dramatic increase in TIMP-2 level in the conditioned medium. However, this slightly reduced TIMP-2 binding is not sufficient to account for the fivefold increase in TIMP-2 concentration in the conditioned medium, therefore supporting an inhibition of the type IV collagenstimulated TIMP-2 degradation by GI129471. 
Figure 9: Degradation and binding of TIMP-2 by HT1080 cells. ${ }^{125}$ I-rTIMP-2 was added to cell-free culture medium (Med) or HT1080 cells plated on plastic (Plast) or type IV collagen (Col IV, $20 \mu \mathrm{g} / w e l l)$. After 24 and $48 \mathrm{~h}$, conditioned media and total cell extracts were collected and subjected to SDS-PAGE (A and B) and $\gamma$ counting (C). (A) Conditioned media harvested after $24 \mathrm{~h}$ were subjected to SDS-15\% PAGE followed by autoradiography of the gel. Arrow, intact ${ }^{125}$ I-rTIMP-2; arrowhead, degraded ${ }^{125}$ I-rTIMP-2. (B) Percentages of degraded ${ }^{125}$ I-rTIMP-2 were calculated after scanning densitometry of the autoradiographs of conditioned media harvested after 24 and $48 \mathrm{~h}$. (C) ${ }^{125}$ I-rTIMP-2 binding to HT1080 cells after 24 and $48 \mathrm{~h}$ was quantified by measuring total cell-extract-associated radioactivity. Specific binding was calculated as the difference between bound radioactivity in the presence and in the absence of cells (nonspecific). Results are expressed as the mean $\pm S D \%$ of ${ }^{125}$ I-rTIMP-2 concentrations. (D) HT1080 cells plated on type IV collagen were treated for up to $48 \mathrm{~h}$ with(@)or without $(\mathrm{O}) 1 \mathrm{H}$ M GI129471. TIMP-2 concentrations in the conditioned media (CM) and total cell extracts (CE, inset) were assessed by ELISA.
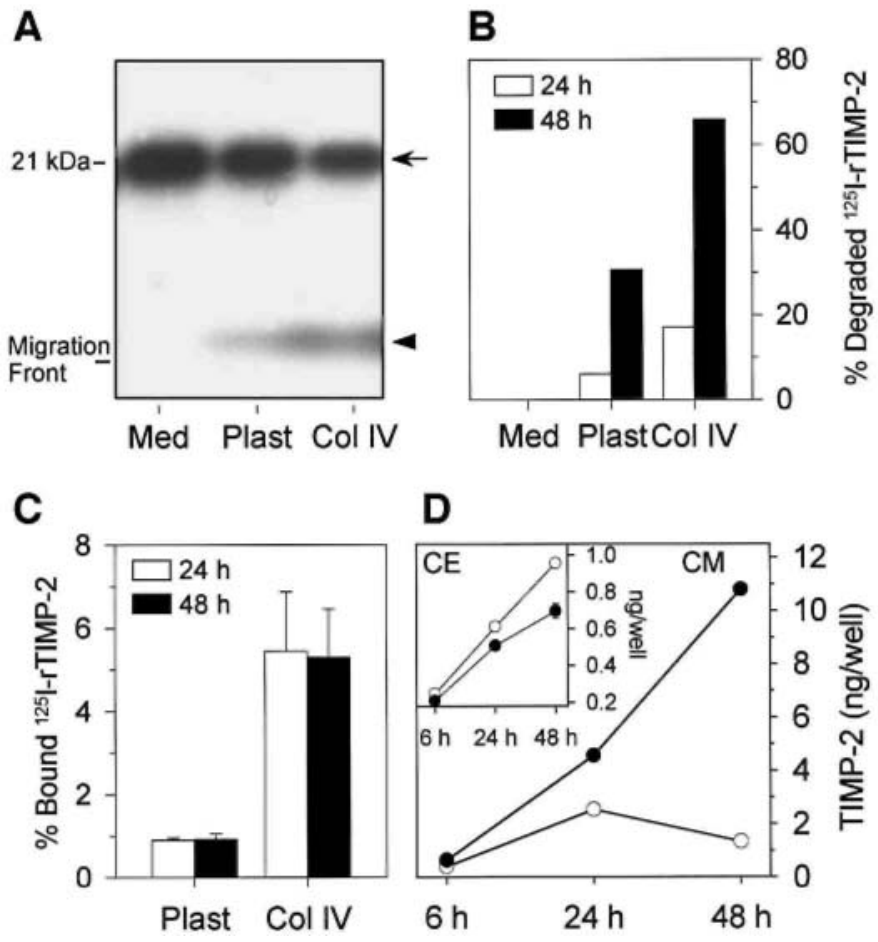

\section{DISCUSSION}

In the present study, we investigated the potential influence of ECM components on pro-MMP-2 activation by HT1080 cells, a human fibrosarcoma cell line. This ECM-mediated activation was compared with the processing induced by two previously described non-physiological MMP-2 activators: TPA and ConA.

\section{MMP-2 Activation by TPA- and ConA-Treated HT1080 Cells}

When HT1080 cells were plated on plastic, zymo-graphic analysis revealed that MMP-2 was essentially secreted in an inactive 66-kDa proform. Nevertheless, the presence of 62-kDa intermediate MMP-2 form as well as the detection by Western blotting of some activated $(60 \mathrm{kDa})$ MT1-MMP in cell extract suggests that, under basal conditions, HT1080 cells are constitutively able to perform the first MT1-MMP-dependent step of pro-MMP-2 activation. It should be noted that the appearance of this intermediate MMP-2 form coincides with a slight decrease of TIMP-2 secretion and the parallel increase of cell-bound TIMP-2 (Fig. 7A). These data are in agreement with previous observations that cell-associated TIMP-2 is required for pro-MMP-2 activation [20, 28, 53].

As previously reported by others $[6,13,15,56-58]$, we showed that TPA- or ConA-treated HT1080 cells increased MT1-MMP mRNA expression and substantially upregulated MT1-MMP protein synthesis. Furthermore, both treatments induced the formation of a 43-kDa MT1-MMP species (Figs. 6A and 6B, lanes 24). The occurrence of this latter form has been associated with the ability of the cells to activate MMP-2 and to degrade gelatin $[13,29,59]$. Consistent with these data, our results also demonstrated an obvious association 
between the TPA- and ConA-induced pro-MMP-2 activation and MT1-MMP processing into a 43-kDa form. Indeed, the level of the $43-\mathrm{kDa}$ species more precisely correlates with the appearance of the fully mature $59-\mathrm{kDa}$ MMP-2 form (compare Fig. 1A, lanes 7-9, and Fig. 6B, lanes 2-4). In this respect, it is interesting to note that even if both TPA and ConA treatments induced the formation of the 62-kDa intermediate MMP-2, only ConA efficiently converted this intermediate into the mature 59-kDa form, as previously reported by Gervasi and coworkers [56]. The ability of ConA to promote the second step of MMP-2 activation (i.e., the intermolecular autolytic cleavage) has been ascribed, at least in part, to its potential to cluster membrane glycoproteins, including MT1-MMP, thereby favoring the autoproteolytic processing of adjacent MT1-MMP-associated intermediate MMP-2 species [56, 60, 61].

\section{Type IV Collagen Induces the Formation of Mature 59-kDa MMP-2}

When HT1080 cells were plated in contact with different ECM proteins, pro-MMP-2 activation was only stimulated by type I or type IV collagens. Indeed, while fibronectin and laminin failed to modulate the MMP-2 activation observed on plastic, type I and type IV collagens induced the processing of the intermediate MMP-2 form to the fully mature 59-kDa species. Our experimental data contrast with the results of Stanton and coworkers reporting that the culture of HT1080 cells on fibronectin (but not laminin) promoted pro-MMP-2 activation [62]. This discrepancy might be a consequence of some clonal modifications of the cellular phenotype of this cell line. In agreement with this hypothesis, it is worth noting that Stanton and coworkers reported that HT1080 cells treated with phor-bol ester processed pro-MMP-2 into the 59-kDa fully mature form. In our cell culture model, and in agreement with others [56], a similar treatment promoted the generation of the $62-\mathrm{kDa}$ intermediate MMP-2 species without any significant further conversion into the mature form.

Compared to the nonphysiological activators mentioned above, collagen-mediated MMP-2 processing required longer incubation periods and did not involve any transcriptional modulation of MMP-2, MT1-MMP, or TIMP-2 expression. We previously demonstrated that, in HT1080 cells, the type IV collagen-mediated pro-MMP-2 activation into the 59-kDa mature form was associated with the level of 60-kDa active MT1-MMP species [27]. However, neither type I nor type IV collagens were able to modify the MT1-MMP synthesis or activation observed in cells plated on plastic (Figs. 6A and 6B, lanes 2, 5, and 6). This observation strongly suggests that, in addition to active $60-\mathrm{kDa}$ MT1-MMP, other factor(s) are required to fully activate pro-MMP-2.

\section{Relationship between TIMP-2 Concentration in the Conditioned Medium and Pro-MMP-2 Activation}

On the basis of the dual role of TIMP-2 during MMP-2 activation, promoting MMP-2 activation when present at low concentrations $[20,29,31,54,63,64]$, but acting as an efficient inhibitor of this process when present at higher doses [19, 20, 26, 31, 53, 65-67], we hypothesized that modulations of TIMP-2 concentration could play important roles in the regulation of MMP-2 processing. Consequently, we investigated the modifications of both TIMP-2 concentration and distribution between conditioned media and cell extracts induced by MMP-2activating treatments. In agreement with recently published data [29, 30], the lower level of secreted TIMP-2, together with the sharply increased cell-associated TIMP-2 concentration observed in ConA-treated HT1080 cells (Fig. 7E) suggests that ConA, by increasing MT1-MMP activation (Fig. 6B, lane 4), triggers the docking of secreted TIMP-2 to the cell surface. In contrast, TPA treatment dramatically decreased the level of secreted TIMP-2 without significantly stimulating its binding to the cell surface (Fig. 7D). We recently demonstrated that this low concentration of secreted TIMP-2 resulted from an MT1-MMP-dependent internalization of TIMP-2 associated with an intracellular degradation process [54]. When HT1080 cells were plated on type IV collagen, the cell-associated TIMP-2 concentration was slightly increased (Figs. 7F and 9C). However, this increase was not sufficient to account for the sharply decreased concentration of TIMP-2 in the conditioned medium. We demonstrated here that this decreased level of secreted TIMP-2 essentially results from an enhanced degradation of TIMP-2 triggered by type IV collagen (Fig. 9B). Interestingly, the concentration of TIMP-2 in conditioned media is modulated by the amount of coated type IV collagen (Fig. 8) and is inversely related to the extent of MMP-2 activation (compare Figs. 8 and 2). Whether this modulation of TIMP-2 concentration is a cause or a consequence of MMP-2 activation remains to be elucidated.

\section{MMP-2 Activation by Type TV Collagen: A Hypothetical Mechanism}

The stimulation of MMP-2 activation induced by type IV collagen displayed a bell-shaped dose-response curve: increasing for collagen concentrations ranging from 1 to $10 \mu \mathrm{g}$ and then progressively decreasing at higher concentrations (Fig. 2). Interestingly, a similar dose-dependent modulation of MMP-2 activation has previously been reported with heparin [68]. Due to its ability to bind MMP-2, heparin promotes the intermolecular MMP-2 autocatalytic cleavage by bringing closer MMP-2 molecules present in solution. It is therefore tempting to 
speculate that, in our culture model, collagen molecules can have a similar function. Indeed, in agreement with our observations (Fig. 3), Allan and co-workers [69] demonstrated that both pro- and active MMP-2 efficiently bind to thin coats of type I and type IV collagens, but very poorly to fibronectin. This collagen-binding property is solely mediated by the fi-bronectin-type II inserts present in the catalytic domain of the enzyme [69]. As a consequence, the interaction of cell surface anchored MMP-2 with the molecules of type IV collagen is likely to induce the clustering of the MT1-MMP/TIMP-2/MMP-2 ternary complexes at the sites of interaction with the ECM, therefore promoting the intermolecular autocatalytic cleavage required to generate fully mature MMP-2. Alternatively, the transmembrane/cytoplasmic domain of MT1-MMP was previously shown to mediate its localization in invadopodia (specialized membrane extensions present at the sites where invading cells are in close contact with the ECM) where it can interact with several other proteins including integrins [61, 70]. Consequently, binding of HT1080 cells to collagen molecules via members of the integrin family could trigger the clustering of invadopodia-associated MT1-MMPs therefore promoting MMP-2 maturation. Interestingly, increasing concentrations of ECM components have been shown to enhance integrin binding and clustering, leading to a progressive decrease of MMP-2 activation by human capillary endothelial cells (Yan et al., personal communication). A similar mechanism is probably responsible for the lower MMP-2 activation observed here in the presence of high collagen concentrations (Fig. 2).

\section{Type IV Collagen-Mediated MMP-2 Activation Is Associated with Invasion of HT1080 Cells}

We have previously demonstrated that active MMP-2 was required for HT1080 cells to invade through type IV collagen coated Transwell cell culture inserts [27]. By using a similar in vitro invasion model, we demonstrated here a close association between the inhibition of both chemoinvasion and pro-MMP-2 activation by rTIMP-2 or GI129471 (Fig. 8), strongly suggesting that this type IV collagen-mediated pro-MMP-2 activation might represent a physiologically relevant system. This observation contrasts with the effect of ConA which, despite its high efficiency to promote pro-MMP-2 activation, failed to induce both degradation and invasion of the ECM [61].

Altogether, these data suggest that, in contrast to the previously published mechanisms accounting for the induction of MMP-2 activation by ECM components [42-44, 62], the promoting effect of type IV collagen does involve neither an upregulation of MT1-MMP transcription nor a posttranslational modification of MT1-MMP. It can be hypothesized that type IV collagen mediates its effect by bringing closer cell membrane-associated MT1-MMP/TIMP-2/MMP-2 complexes, therefore promoting the intermolecular autolytic cleavage of intermediate MMP-2 and thus leading to the generation of the fully mature species. Additionally, type IV collagen decreases the level of secreted TIMP-2, thus potentially furthering the processing of pro-MMP-2 which is known to be inhibited by high TIMP-2 concentrations [20, 31, 53]. It is worth noting that the TIMP-2 degradation process illustrated here potentially represents an additional regulatory mechanism of the proteolytic activity of the cells. Indeed, because the net proteolytic activity reflects the balance between the levels of active proteinases and their corresponding inhibitors [71], the ability of HT1080 cells to degrade TIMP-2 when plated on type IV collagen might alter this balance and, consequently, increase their degradative capacity. Conversely, the accumulation of secreted TIMP-2 observed in the presence of the synthetic MMP inhibitor (Fig. 9D) might contribute to the anti-invasive property of this compound (Fig. 4D).

Gilles and co-workers [72] have previously reported that the activation of pro-MMP-2 by two breast carcinoma cell lines was stimulated in the presence of SPARC (secreted protein acidic and rich in cystein)/ osteonectin. Interestingly, this activation did altered neither MT1-MMP mRNA nor protein levels but it was clearly associated with a significant decrease of the level of secreted TIMP-2, suggesting the occurrence of an activation mechanism similar to that induced by type IV collagen in this study.

In conclusion, our results reveal that the interactions between type IV collagen and human fibrosarcoma cells result in the activation of pro-MMP-2 at the cell surface. As invasive tumor cells must breach BMs at different steps of the metastatic dissemination, the ability of HT1080 cells to activate MMP-2 (a major type IV collagenase) when they encounter type IV collagen might thus represent a key regulatory mechanism for the acquisition of an invasive potential. Whether a similar stimulation of MMP-2 activation by type IV collagen also occurs in more physiological processes (i.e., involving nontransformed cells) remains an open question. 


\section{ACKNOWLEDGEMENTS}

The authors thank J. P. Cherami-Bien and L. Volders for their technical assistance as well as Dr. M.-C. Rio and the late Professor P. Basset (IGBMC, Illkirch, France) for providing anti-MT1-MMP monoclonal antibodies and E. W. Thompson (Lombardi Cancer Center, Georgetown University Medical Centre, Washington, DC) for providing MT1-MMP-transfected COS-1 cells lysates. This work was supported by grants from the Communauté Française de Belgique (Actions de Recherche Concertées), the CGER-Assurances 1996/1999, the Association contre le Cancer, the Association Sportive contre le Cancer, the Loterie Nationale, the Fonds de la Recherche Scientifique Médicale (FRSM), the Fonds d'Investissement de Recherche Scientifique 1997-CHU Liège, the Centre Anticancéreux près de l'Université de Liège and the Fondation Léon Frédéricq, and University of Liège, Liège, all in Belgium; the General RE-Luxembourg; the Commission of European Communities (Concerted European Action Biotech BIO4-CT96-0464), and the Industry (Roche-Boehringer Mannheim $\mathrm{GmbH}$, Germany). E.M. is a recipient of a grant from the Fondation Léon Frédéricq; A.N. is a senior research associate from FNRS.

\section{REFERENCES}

1. Mignatti, P., Robbins, E., and Rifkin, D. B. (1986). Tumor invasion through the human amniotic membrane: Requirement for a proteinase cascade. Cell 47, 487-498.

2. Barsky, S. IT., Siegal, G. P., Jannotta, F., and Liotta, L. (1983). Loss of basement membrane components by invasive tumors but not by their benign counterparts. Lab. Invest. 49, 140-147.

3. Liotta, L. A., Rao, C. N, and Barsky, S. H. (1983). Tumor invasion and the extracellular matrix. Lab. Invest. 49, 636-649.

4. Stetler-Stevenson, W. G., Liotta, L. A., and Kleiner, D. E. (1993). Extracellular matrix 6: Role of matrix metalloprotein-ases in tumor invasion and metastasis. FASEB J. 7, 1434-1441.

5. Duffy, M. J. (1992). The role of proteolytic enzymes in cancer invasion and metastasis. Clin. Exp. Metastasis 10, 145-155.

6. Yu, A. E., Hewitt, R. E., Kleiner, D. E., and Stetler-Stevenson, W. G. (1996). Molecular regulation of cellular invasion-role of gelatinase A and TIMP-2. Biochem. Cell. Biol. 74, 823-831.

7. Itoh, T., Tanioka, M., Yoshida, H, Yoshioka, T., Nishimoto, H, and Itohara, S. (1998). Reduced angiogenesis and tumor progression in gelatinase A-deficient mice. Cancer Res. 58, 1048-1051.

8. Stetler-Stevenson, W. G. (1995). Progelatinase A activation during tumor cell invasion. Invasion Metast. 14, $259-268$.

9. Nagase, H. (1997). Activation mechanisms of matrix metallo-proteinases. Biol. Chem. 378, 151-160.

10. Brown, P. D., Bloxidge, R. E., Stuart, N. S. A., Gatter, K. C, and Carmichael, J. (1993). Association between the expression of activated 72-kilodalton gelatinase and tumor spread in non-small-cell lung carcinoma. J. Natl. Cancer Inst. 85, 574-578.

11. Davies, B., Waxman, J., Wasan, H, Abel, P., Williams, G., Krausz, T., Neal, D., Thomas, D., Hanby, A., and Balkwill, F. (1993). A synthetic matrix metalloproteinase inhibitor decreases tumor burden and prolongs survival of mice bearing human ovarian carcinoma xenografts. Cancer Res. 53, 5365-5369.

12. Nomura, H, Fujimoto, N, Seiki, M., Mai, M., and Okada, Y. (1996). Enhanced production of matrix metalloproteinases and activation of matrix metalloproteinase-2 (gelatinase A) in human gastric carcinomas. Int. J. Cancer 69, 9-16.

13. Lohi, J., Lehti, K, Westermarck, J., Kähäri, V.M., and Keski-Oja, J. (1996). Regulation of membrane-type matrix metallopro-teinase-1 expression by growth factors and phorbol 12-myris-tate 13-acetate. Eur. J. Biochem. 239, 239-247.

14. Migita, K, Eguchi, K, Kawabe, Y., Ichinose, Y., Tsukada, T., Aoyagi, T., Nakamura, H, and Nagataki, S. (1996). TNF- $\alpha$ mediated expression of membrane-type matrix metalloproteinase in rheumatoid synovial fibroblasts. Immunology 89, $553-557$.

15. Yu, M., Sato, H., Seiki, M., and Thompson, E. W. (1995). Complex regulation of membrane-type matrix metalloproteinase expression and matrix metalloproteinase-2 activation by con-canavalin A in MDA-MB-231 human breast cancer cells. Cancer Res. 55, $3272-3277$.

16. Ailenberg, M., and Silverman, M. (1996). Cellular activation of mesangial gelatinase A by cytochalasin D is accompanied by enhanced mRNA expression of both gelatinase A and its membrane-associated gelatinase A activator (MT-MMP). Biochem. J. 313, 879-884.

17. Overall, C. M., and Sodek, J. (1990). Concanavalin A produces a matrix-degradative phenotype in human fibroblasts: Induction and endogenous activation of collagenase, 72-kDa gelatinase, and Pump-1 is accompanied by the suppression of tissue inhibitor of matrix metalloproteinase. J. Biol. Chem. 265, 21141-21151. 
18. Ward, R. V., Atkinson, S. J., Slocombe, P. M., Docherty, A. J. P., Reynolds, J. J., and Murphy, G. (1991). Tissue inhibitor of metalloproteinases-2 inhibits the activation of 72-kDa progela-tinase by fibroblast membranes. Biochem. Biophys. Acta 1079, $242-246$.

19. Strongin, A. Y., Marmer, B. L., Grant, G. A., and Goldberg, G. I. (1993). Plasma membrane-dependent activation of the 72-kDa type IV collagenase is prevented by complex formation with TIMP-2. J. Biol. Chem. 268, 14033-14039.

20. Strongin, A. Y., Collier, I., Bannikov, G., Marmer, B. L., Grant, G. A., and Goldberg, G. I. (1995). Mechanism of cell surface activation of 72-kDa type IV collagenase. J. Biol. Chem. 270, 5331-5338.

21. Brown, P. D., Levy, A. T., Margulies, I. M. K., Liotta, L. A., and Stetler-Stevenson, W. G. (1990). Independent expression and cellular processing of Mr 72,000 type IV collagenase and interstitial collagenase in human tumorigenic cell lines. Cancer Res. 50, 6184-6191.

22. Sato, H., Takino, T., Okada, Y., Cao, J., Shinagawa, A., Yamamoto, E., and Seiki, M. (1994). A matrix metalloproteinase expressed on the surface of invasive tumour cells. Nature 370, 61-65.

23. Cao, J., Sato, H., Takino, T., and Seiki, M. (1995). The C-terminal region of membrane type matrix metalloproteinase is a functional transmembrane domain required for pro-gelati-nase A activation. J. Biol. Chem. 270, 801-805.

24. Sato, H., Takino, T., Kinoshita, T., Imai, K., Okada, Y., Stetler-Stevenson, W. G., and Seiki, M. (1996). Cell surface binding and activation of gelatinase A induced by expression of membrane-type-1-matrix metalloproteinase (MT1-MMP). FEBS Lett. 385, 238-240.

25. Sato, H., and Seiki, M. (1996). Membrane-type matrix metalloproteinase (MT-MMPs) in tumor metastasis. J. Biochem. 119, $209-215$.

26. Pei, D., and Weiss, S. J. (1996). Transmembrane-deletion mutants of the membrane-type matrix metalloproteinase-1 process progelatinase A and express intrinsic matrix-degrading activity. J. Biol. Chem. 271, 9135-9140.

27. Maquoi, E., Noël, A., Frankenne, F., Angliker, H., Murphy, G., and Foidart, J.-M. (1998). Inhibition of matrix metalloproteinase 2 maturation and HT1080 invasiveness by a synthetic furin inhibitor. FEBS Lett. 424, 262-266.

28. Butler, G. S., Butler, M. J., Atkinson, S. J., Will, H., Tamura, T., Schade van Westrum, S., Crabbe, T., Clements, J., d'Ortho, M.P., and Murphy, G. (1998). The TIMP-2 membrane type 1 metalloproteinase "receptor" regulates the concentration and efficient activation of progelatinase A. J. Biol. Chem. 273, 871-880.

29. Cowell, S., Knàuper, V., Stewart, M. L., d'Ortho, M.P., Stanton, H., Hembry, R. M., Lopez-Otin, C, Reynolds, J. J., and Murphy, G. (1998). Induction of matrix metalloproteinase activation cascades based on membrane-type 1 matrix metalloproteinase: Associated activation of gelatinase A, gelatinase B and collagenase 3. Biochem. J. 331, 453-458.

30. Zucker, S., Drews, M., Conner, C, Foda, H. D., DeClerck, Y. A., Langley, K. E., Bahou, W. F., Docherty, A. J. P., and Cao, J. (1998). Tissue inhibitor of metalloproteinase-2 (TIMP-2) binds to the catalytic domain of the cell surface receptor, membrane type 1-matrix metalloproteinase 1 (MT1-MMP). J. Biol. Chem. 273, 1216-1222.

31. Atkinson, S. J., Crabbe, T., Cowell, S., Ward, R. V., Butler, M. J., Sato, H., Seiki, M., Reynolds, J. J., and Murphy, G. (1995). Intermolecular autolytic cleavage can contribute to the activation of progelatinase A by cell membranes. J. Biol. Chem. 270, 30479-30485.

32. Baramova, E. N, Bajou, K., Remacle, A., L'Hoir, C, Krell, H. W., Weidle, U. H., Noël, A., and Foidart, J. M. (1997). Involvement of $\mathrm{PA} /$ plasmin system in the processing of pro-MMP-9 and in the second step of pro-MMP-2 activation. FEBS Lett. 405, $157-162$.

33. Hynes, R. O. (1992). Integrins: Versatility, modulation, and signalling in cell adhesion. Cell 69, 11-25.

34. Damsky, C. H., Sutherland, A., and Fisher, S. J. (1993). Extracellular matrix 5: Adhesive interactions in early mammalian embryogenesis, implantation, and placentation. FASEB J. 7, 1320-1329.

35. Werb, Z. (1997). ECM and cell surface proteolysis: Regulating cellular ecology. Cell 91, 439-442.

36. Heino, J. (1996). Biology of tumor cell invasion: Interplay of cell adhesion and matrix degradation. Int. J. Cancer 65, 717-722.

37. Sang, Q.X., Thompson, E. W., Grant, D., Stetler-Stevenson, W. G., and Byers, S. W. (1991). Soluble laminin and arginine-glycineaspartic acid containing peptides differentially regulate type IV collagenase messenger RNA, activation, and localization in testicular cell culture. Biol. Reprod. 45, 387-394.

38. Teti, A., Farina, A. R., Villanova, I., Tiberio, A., Tacconelli, A., Sciortino, G., Chambers, A. F., and Mackay, A. R. (1998). Activation of MMP-2 by human GCT23 giant cell tumour cells induced by osteopontin, bone sialoprotein and GRGDSP peptides is RGD and cell shape change dependent. Int. J. Cancer 77, 82-93.

39. Azzam, H. S., and Thompson, E. W. (1992). Collagen-induced activation of the Mr 72,000 type IV collagenase in normal and malignant human fibroblastoid cells. Cancer Res. 52, 4540-4544.

40. Thompson, E. W., Yu, M., Bueno, J., Jin, L., Maiti, S. N., Palao-Marco, F. L., Pulyaeva, H., Tamborlane, J. W., Tirgari, R., Wapnir, I., and Azzam, H. (1994). Collagen induced MMP-2 activation in human breast cancer. Breast Cancer Res. Treat. 31, $357-370$. 
41. Seltzer, J. L., Lee, A. Y., Akers, K. T., Subdeck, B., Southon, E. A., Wayner, E. A., and Eisen, A. Z. (1994). Activation of 72-kDa type IV collagenase/gelatinase by normal fibroblasts in collagen lattices is mediated by integrin receptors but is not related to lattice contraction. Exp. Cell Res. 213, 365-374.

42. Gilles, C, Polette, M., Seiki, M., Birembaut, P., and Thompson, E. W. (1997). Implication of collagen type I-induced membrane-type 1-matrix metalloproteinase expression and matrix metalloproteinase-2 activation in the metastatic progression of breast carcinoma. Lab. Invest. 76, 651-660.

43. Tomasek, J. J., Halliday, N. L., Updike, D. L., Ahern-Moore, J. S., Vu, T.-K. H., Liu, R. W., and Howard, E. W. (1997). Gelatinase A activation is regulated by the organization of the polymerized actin cytoskeleton. J. Biol. Chem. 272, 7482-7487.

44. Haas, T. L., Davis, S., and Madri, J. A. (1998). Three-dimensional type I collagen lattices induce coordinate expression of matrix metalloproteinases MT1-MMP and MMP-2 in microvascular endothelial cells. J. Biol. Chem. 273, 3604-3610.

45. DeClerck, Y. A., Yean, T.D., Chan, D., Shimada, H, and Langley, K. E. (1991). Inhibition of tumor invasion of smooth muscle cell layers by recombinant human metalloproteinase inhibitor. Cancer Res. 51, 2151-2157.

\section{Campion, C, Dickens, J. P., and Crimmin, M. J. (1990). Patent WO 90/05719.}

47. Timpl, R., Bruckner, P., and Fietzek, P. (1979). Characterization of pepsin fragments of basement membrane collagen obtained from a mouse tumor. Eur. J. Biochem. 95, 255-263.

48. Yamada, K. M. (1983). Isolation of fibronectin from plasma and cells. In "Immunochemistry of the Extracellular Matrix" (H. Furthmayr Ed.). CRC Press, Boca Raton, FL.

49. Delvoye, P., Nusgens, B., and Lapière, Ch.M. (1983). The capacity of retracting a collagen matrix is lost by dermatosparac-tic skin fibroblasts. J. Invest. Dermatol. 81, 267-270.

50. Noël, A., Hajitou, A., L'Hoir, C, Maquoi, E., Baramova, E., Lewalle, J.-M., Remacle, A., Brown, P., Calberg-Bacq, C.-M., and Foidart, J.-M. (1998). Inhibition of stromal matrix metal-loproteinases: Effects on breast tumor progression by fibroblasts. Int. J. Cancer 76, 267-273.

51. Jensenius, J. C, Andersen, I., Hau, J., Crone, M., and Koch, C. (1981). Eggs: Conveniently packaged antibodies-Methods for purification of yolk IgG. J. Immunol. Methods 46, 63-68.

52. Lehti, K., Lohi, J., Valtanen, H., and Keski-Oja, J. (1998). Proteolytic processing of membrane-type-1 matrix metallopro-teinase is associated with gelatinase A activation at the cell surface. Biochem. J. 334, 345-353.

53. Kinoshita, T., Sato, H., Okada, A., Ohuchi, E., Imai, K., Okada, Y., and Seiki, M. (1998). TIMP-2 promotes activation of progelatinase A by membrane-type 1 matrix metalloproteinase immobilized on agarose beads. J. Biol. Chem. 273, 16098-16103.

54. Maquoi, E., Frankenne, F., Baramova, E., Munaut, C, Souni, N. E., Noël, A., and Foidart, J. M. (2000). Membrane type 1-matrix metalloproteinase (MT1-MMP)-associated degradation of tissue inhibitor of metalloproteinase 2 (TIMP-2) in human tumor cell lines. $J$. Biol. Chem. 275, 11368-11378.

55. Botos, I., Scapozza, L., Zhang, D., Liotta, L. A., and Meyer, E. F. (1996). Batimastat, a potent matrix metalloproteinase inhibitor, exhibits an unexpected mode of binding. Proc. Natl. Acad. Sci. USA 93, 2749-2754.

56. Gervasi, D. C, Raz, A., Dehem, M., Yang, M., Kurkinen, M., and Fridman, R. (1996). Carbohydrate-mediated regulation of matrix metalloproteinase-2 activation in normal human fibroblasts and fibrosarcoma cells. Biochem. Biophys. Res. Commun. 228, 530-538.

57. Lim, Y.-T., Suguira, Y., Laug, W. E., Sun, B., Garcia, A., and DeClerck, Y. A. (1996). Independent regulation of matrix metalloproteinases and plasminogen activators in human fibrosarcoma cells. J. Cell. Physiol. 167, 333-340.

58. Yamamoto, M., Mohanam, S., Sawaya, R., Fuller, G. N, Seiki, M., Sato, H., Gokaslan, Z. L., Liotta, L. A., Nicolson, G. L., and Rao, J. S. (1996). Differential expression of membrane-type matrix metalloproteinase and its correlation with gelatinase A activation in human malignant brain tumors in vivo and in vitro. Cancer Res. 56, 384-392.

59. d'Ortho, M.P., Stanton, H., Butler, M., Atkinson, S., and Murphy, G. (1998). MT1-MMP on the cell surface causes focal degradation of gelatin films. FEBS Lett. 421, 159-164.

60. Yu, M., Sato, H., Seiki, M., Spiegel, S., and Thompson, E. W. (1997). Tyrosine phosphorylation mediates ConA-induced membrane type 1-matrix metalloproteinase expression and matrix metalloproteinase-2 activation in MDA-MB-231 human breast carcinoma cells Cancer Res. 57, 5028-5032.

61. Nakahara, H., Howard, L., Thompson, E. W., Sato, H, Seiki, M., Yeh, Y., and Chen, W.-T. (1997). Transmembrane/cytoplasmic domain-mediated membrane type 1-matrix metallopro-tease docking to invadopodia is required for cell invasion. Proc. Natl. Acad. Sci. USA 94, 7959-7964. 
62. Stanton, H, Gavrilovic, J., Atkinson, S. J., D'Ortho, M. P., Yamada, K. M., Zardi, L., and Murphy, G. (1998). The activation of proMMP-2 (gelatinase A) by HT1080 fibrosarcoma cells is promoted by culture on a fibronectin substrate and is concomitant with an increase in processing of MT1-MMP (MMP-14) to a $45 \mathrm{kDa}$. J. Cell Sci. 111, 2789-2798.

63. Emmert-Buck, M. R., Emonard, H, Corcoran, M. L., Krutzsch, H. C, Foidart, J.-M., and Stetler-Stevenson, W. G. (1995). Cell surface binding of TIMP-2 and pro-MMP-2/TIMP-2 complex. FEBS Lett. 364, $28-32$.

64. Imai, K., Ohuchi, E., Aoki, T., Nomura, H, Fujii, Y., Sato, H, Seiki, M., and Okada, Y. (1996). Membrane-type matrix metalloproteinase 1 is a gelatinolytic enzyme and is secreted in a complex with tissue inhibitor of metalloproteinase 2. Cancer Res. 56, 27072710 .

65. Cao, J., Rehemtulla, A., Bahou, W., and Zucker, S. (1996). Membrane type matrix metalloproteinase 1 activates pro-gela-tinase A without furin cleavage of the N-terminal domain. J. Biol. Chem. 271, 30174-30180.

66. Sato, H., Kinoshita, T., Takino, T., Nakayama, K, and Seiki, M. (1996). Activation of a recombinant membrane type 1-matrix metalloproteinase (MT1 -MMP) by furin and its interaction with tissue inhibitor of metalloproteinases (TIMP)-2. FEBS Lett. 393, $101-104$.

67. Will, H., Atkinson, S. J., Butler, G. S., Smith, B., and Murphy, G. (1996). The soluble catalytic domain of membrane type 1 matrix metalloproteinase cleaves the propeptide of progelati-nase A and initiates autoproteolytic activation. J. Biol. Chem. 271, 17119-17123.

68. Crabbe, T., Ioannou, C, and Docherty, A. J. P. (1993). Human progelatinase A can be activated by autolysis at a rate that is concentration-dependent and enhanced by heparin bound to the C-terminal domain. Eur. J. Biochem. 218, 431-438.

69. Allan, J. A., Docherty, A. J. P., Barker, P. J., Huskisson, N. S., and Reynolds, J. J. (1995). Binding of gelatinases A and B to type-I collagen and other matrix components. Biochem. J. 309, 299-306.

70. Chen, W.-T. (1996). Proteases associated with invadopodia, and their role in degradation of extracellular matrix. Enzyme Protein 49, $59-71$.

71. Liotta, L. A., Stetler-Stevenson, W. C, and Steeg, P. S. (1991). Cancer invasion and metastasis: Positive and negative regulatory elements. Cancer Invest. 9, 543-551.

72. Gilles, C, Bassuk, J. A., Pulyaeva, H, Sage, E. H, Foidart, J. M., and Thompson, E. W. (1998). SPARC/osteonectin induces matrix metalloproteinase 2 activation in human breast cancer cell lines. Cancer Res. 58, 5529-5536. 